\title{
Environmental and recycling education at Tamagawa University*
}

\author{
Yuji Suzuki ${ }^{* 1}$, Natsuo Suzuki*2, Ryo Miyakoshi*1 and Hidetoshi Ohkubo ${ }^{{ }^{*}, *_{2}}$ \\ • Graduate School of Mechanical Engineering, Tamagawa University \\ ${ }^{2}$ Department of Mechanical Engineering, Tamagawa University \\ Machida, Tokyo, 194-8610, Japan \\ E-mail:szkyu8is@engs.tamagawa.ac.jp
}

\begin{abstract}
One of the most important and effective methods for studying is that students themselves plan and study what they want to study, and this learning process is very important for imparting to them the spirit of engineers. However most of the subject matter is prepared for students beforehand in ordinary courses at typical universities, where students have only to select them. Authors wished to create a course in which students can research on what they want to study. They developed a novel course called "a special course for active students" about a decade ago. This paper presents the framework and several actual activities of the developed course, especially for regional environmental improvement and energy education.
\end{abstract}

Key words: Environmental Education, Recycling Education, Special Course for active Students

\section{Introduction}

In recent years, university education system has been evolving, shedding the conventional education methods to foster capabilities of students for solving problems that are directly related to our lives. Such a need has been clearly indicated in ministerial ordinance came into effect in September 1999, as well as being documented as a selection criteria by Japan Accreditation Board for Engineering Education (JABEE) published in November, 1999.

To develop such talents, a free style method of education is needed, which is not bounded by the framework of the conventional education system. The present educational system is such that a student is required to learn the process of solving a problem by first identifying the reason behind it and then collecting the required knowledge.

In the faculty of engineering at Tamagawa University, a course named "Special course for active students" was developed and put to practice with the aim of promoting the concept that students can engage themselves to learn what they want by planning, studying and researching the subject ${ }^{1)-4)}$.

Here, we report on the activities in environmental and recycling education at the engineering faculty of Tamagawa University, carried out under our "Special course for active students".

\section{Special course for active students}

Engineering education has a vital role to play as it provides the foundation for the 


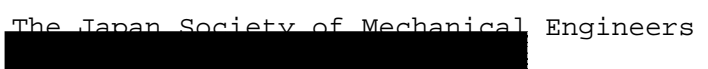

Japanese manufacturing industry. However, the field of engineering has progressed enormously and has become divided into specialized fields. Therefore, the subjects one has to learn are piled up hierarchically, which makes some students to lose their objectives after entering university. From the time of its establishment in 1929, Tamagawa University has consistently practiced what is known as the 'all-round-education'. It is a method of education that aims at training students to be excellent human beings besides their formal education.

As a part of the trial of a concrete curriculum for the all-round-education, a subject based on "Special course for Education" was established, in which students take the lead in solving problems. The subject was launched and its activities conducted first at the faculty of engineering of Tamagawa University. Participation in these activities was not just restricted to the students from the engineering faculty, but also departments of the literature and agriculture were asked to take part so as to cover the entire university. The results of the activities were reported through presentation of proposals, writing reports and poster presentation in the campus festivals. The students, who took the subject, did not just passively learn about topics that had been selected for them. But rather, they engaged themselves in active learning and research process right from the starting point of the planning stage through to other stages, where they were required to independently think and try to resolve problems.

\subsection{Environment activities}

Presently, concerns on environmental issues including the global warming are on the rise. For example, industries independently have introduced, as the business management techniques, "environment management and auditing" in order reduce their environmental burden. The international organization for standardization (ISO) has formally standardized ISO-14000 series. Therefore, strengthening of the efforts on solving environmental issues is being demanded. Even at Tamagawa campus, environmental policy is chosen as one of the education policies. Further at the university, the awareness on environmental issues has been elevated by the education on how to cultivate various abilities, using the environment as the subject in focus. The abilities of interest here are: the ability to contemplate deeply about the effects of the environment on the society; and ability to train how to take the initiative. Through such education, we have deepened the overall understanding and awareness of the interaction between human activities and the environment.

Even the course on "Special course for active students" was conducted as a part of environmental education in a practical manner. Mainly, activities on topics on global environmental problems were conducted in the course. The students, who participated in the activities considered environmental issues as if their own problems. Also, they realized the importance of being actively engaged in environmental conservation, not only in the school or home but also in various aspects of their lives. One can say that these research activities made awareness in students as practitioners, rather than as on-lookers.

\subsection{Recycle activities}

This section reports on the recycle activities mainly related to umbrellas, bicycles and used books, which were found to be successful in practice.

Umbrella stands can be found at two locations near the ticket-checking gates of Tamgawa-Gakuen-Mae station on Odakyu railway line. These umbrellas are known as 'goodwill umbrellas', which can be borrowed by the local residents and students freely if they happen to run into unexpected rain while going to work in the mornings or on returning from work. Started in 1979 on a proposition by the neighbourhood association, the 
practice of the goodwill umbrellas has continued to date, and it also happens to be the first instance of making umbrellas available for public use, in Japan. The umbrellas borrowed can be returned when the weather is fine the next day or later, but all of them are not usually returned. Therefore, used umbrellas were mended as a part of the recycling education, which were then donated to the neighbourhood association.

The umbrellas donated by the "Special course for research" program were collected from each of the students, who brought unwanted umbrellas from their homes, and also by asking the school and neighbourhood association to collect broken umbrellas. At first, the participating students were not trained to do the repairs, and therefore, they learned the required skills by first studying the repair methods by visiting web-sites of specialist umbrella-shops and then by practicing. The web-sites provided the student the information such: the basic components of an umbrella and their names, various breakage patterns of umbrella, the degree of difficulty to mend, necessary parts and repair tools, and details related to specific mending methods. In the campus festival, repair demonstrations were performed, and figure 1 shows a snapshot of students being engaged in repairing umbrellas. poster presentations on umbrella-recycling methods surveyed by each member were presented to the visitors. The neighbourhood association of Tamagawa-Campus also visited the campus festival and gave words of encouragement for the recycling work. In addition, the visitors were asked to fill in a questionnaire, in which they are asked about the number of umbrellas one owns, the experience of repairing umbrellas in the form of selective answers and the pros and cons of recycling activities. The questionnaire showed the approval of the umbrella recycling activities, by many visitors. In a ceremony held in front of the umbrella stands, the repaired umbrellas were presented to the neighbourhood association, thus successfully achieving the goal of the umbrella recycling activity. Each year, supporters and collaborators have shown an increase, and recycling activities are still continuing with the goodwill and support of many people.

In the midst of atmospheric pollution and drying up of resources becoming an issue, the bicycle is attracting attention as a green transport means, which will be continued to be used into the future. On the other hand, abandoned bicycles cause disruptions in the living environment of the modern society. Therefore, in the recycle education program, we carried out recycling activities, paying attention to the abandoned-bicycle problem, which is all around us. In practice, students strolled in their neighborhood or in the area surrounding the Tamagawa railway station, and came up with a proposal for the method of bicycle recycling ${ }^{3)}$. Then based on this proposal, they engaged themselves in the activities of bicycle recycling. Figure 2 shows a snapshot of the students being engaged in the bicycle recycle activities. The bicycles repaired were rented out to laboratories in the campus, thus achieving the goal of recycling program.

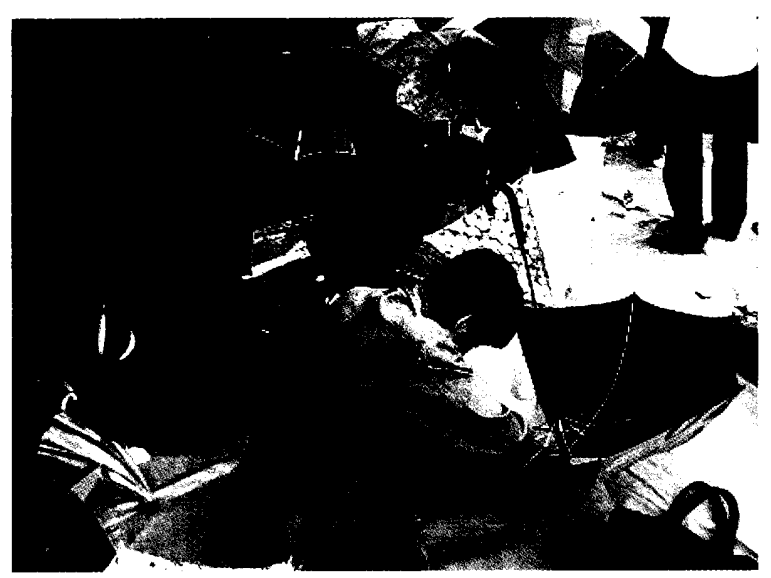

Fig.1 Umbrella recycling activity by students 


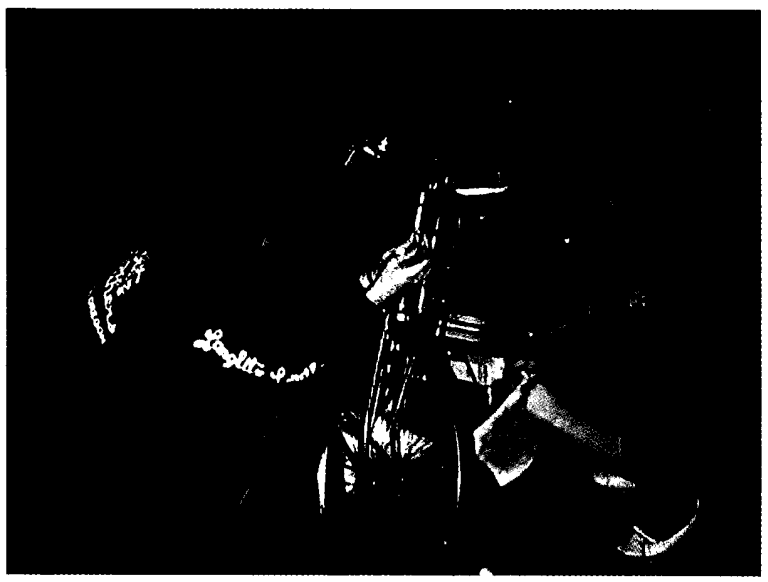

Fig.2 Bicycles recycling activity by students

\section{Energy Contest}

In order to address the energy and global warming issues, cooperation from general public other than scholars and scientists are essential, and in addition, education on energy matters should be spread widely in the society.

One of the authors planned a participatory type "New Star-rating Energy Contest" with the aim of improving the awareness of the environmental and energy issues, and the contest has been conducted four times in four years ${ }^{5), 6}$. The contest was organized as a national-scale annual contest with the cooperation of several professional societies, and its theme and venue change every year. In 2008, the first "New-Star rating Energy Contest" was held at Tamagawa University with the cooperation of the division, 'Technology and Society" of Japan Society of Mechanical Engineers. In 2009, the second contest was also held at Tamagawa University, and national-scale participation was achieved. In 2010, the third contest was held at Kyushu university, and in 2011, the fourth contest at Iwate university.

The authors have taken part in the all four contests so far, and as Table 1 lists, nine themes or ideas have been proposed including the one from by the high school division of Tamagawa campus. Of these entries, the first and second contests resulted in winning encouragement award. The third contest resulted in the first prize for the theme "Ice-cream making machine running down a slope", and the fourth one, two industry awards and an 'executive committee' award.

The fourth contest was held on Nov. 12, 2011 at 'Collabo MIU' center, which is a research and development center and a collaboration of Morioka city and Iwate University. There were energy supply disruptions due to large-scale power failures in the disaster-stricken areas caused by the 'Tohoku earthquake and Tsunami', which occurred on March 11, 2011. In some areas, it took many days before people could enjoy hot meals. To address such emergency situations, the fourth contest was held with the theme, "Cooking methods with effective usage of new star-rated energy" produced by such energy sources as wood-based bio-mass and solar energy.

One of the ideas proposed this time is the utilization of the heat of absorption when moister is absorbed by the capillary action of artificial Zeolite. A schematic diagram of the experimental apparatus is shown in Fig. 3. In an aluminum container, artificial zeolite and a stainless-steel container that holds food are placed, and heat is generated by adding water to zeolite, thus heating the food. The anticipated effect here is that the generation of heat due to the physical moisture absorption by zeolite can be utilized for heating. Further, by 
covering the aluminum container with an insulating material, we aimed at reducing the heat leakage to outside the container as much as possible. In addition, by removing the top lid of the stainless-steel cooking container, the steam generated can be utilized together with the heat in the aluminum container to do steam cooking. If zeolite becomes fully immersed in water, it is not possible to obtain enough heat, and therefore, one has to be careful about the amount of water used.

Table 1 List of participants from Tamagawa Campus and themes

\begin{tabular}{|c|c|c|}
\hline Contest & Campus Division & Theme \\
\hline \multirow[b]{3}{*}{ First } & Tamagawa University & Human-powered Refrigerator \\
\hline & Tamagawa University & Regenerative refrigerator \\
\hline & Tamagawa University & $\begin{array}{l}\text { Hybrid-type low-pressure boiling refrigerator } \\
\text { (Encouragement award) }\end{array}$ \\
\hline \multirow[b]{2}{*}{ Second } & Tamagawa University & $\begin{array}{l}\text { Use of battery-assisted bicycle without a } \\
\text { commercial electrical supply (Encouragement } \\
\text { award) }\end{array}$ \\
\hline & $\begin{array}{l}\text { Tamagawa Campus High } \\
\text { school }\end{array}$ & $\begin{array}{l}\text { Application of solar light and heat for Chocolate } \\
\text { Fondue }\end{array}$ \\
\hline Third & Tamagawa University & $\begin{array}{l}\text { Ice-cream making machine running down a slope } \\
\text { (First prize) }\end{array}$ \\
\hline \multirow{3}{*}{ Fourth } & Tamagawa University & $\begin{array}{l}\text { Zeolite cooker } \\
\text { (Executive committee award) }\end{array}$ \\
\hline & Tamagawa University & $\begin{array}{l}\text { Solar drier } \\
\text { (Toyo Manufacturer's award) }\end{array}$ \\
\hline & Tamagawa University & Stinger-4000 mark2 (Japan-wireless award) \\
\hline
\end{tabular}
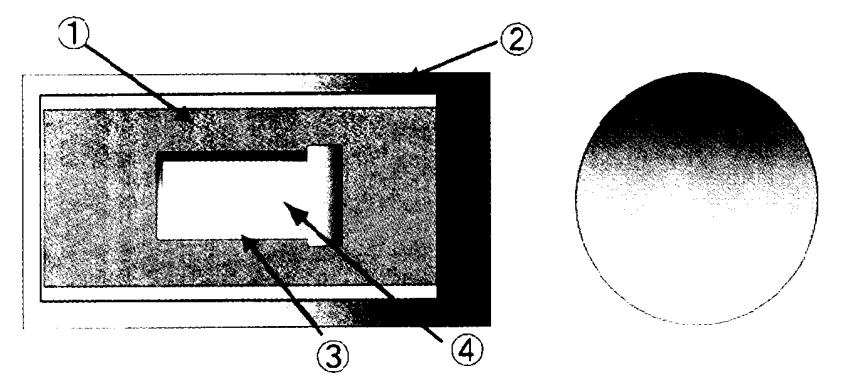

(1) Artificial zeolite (2)Aluminium container
(3) SUS304 container (4)drinks or food

Fig.3 Experimental apparatus for heating by zeolite

Figure 4 shows the history of temperature change within the stainless-steel container. It can be seen that contents of the stainless-steel container can be heated to roughly $70^{\circ} \mathrm{C}$ and maintained at that temperature. By having water and dried-up artificial zeolite in stock before hand, it will be possible to generate heat in stable manner even in a place where there 
is no electricity or gas supply for some reason, irrespective of the state of the weather. It was also found that artificial zeolite can be reused by sufficient drying. As the future development, we are considering the possibility of capturing the vapor generated for use in a steamer.

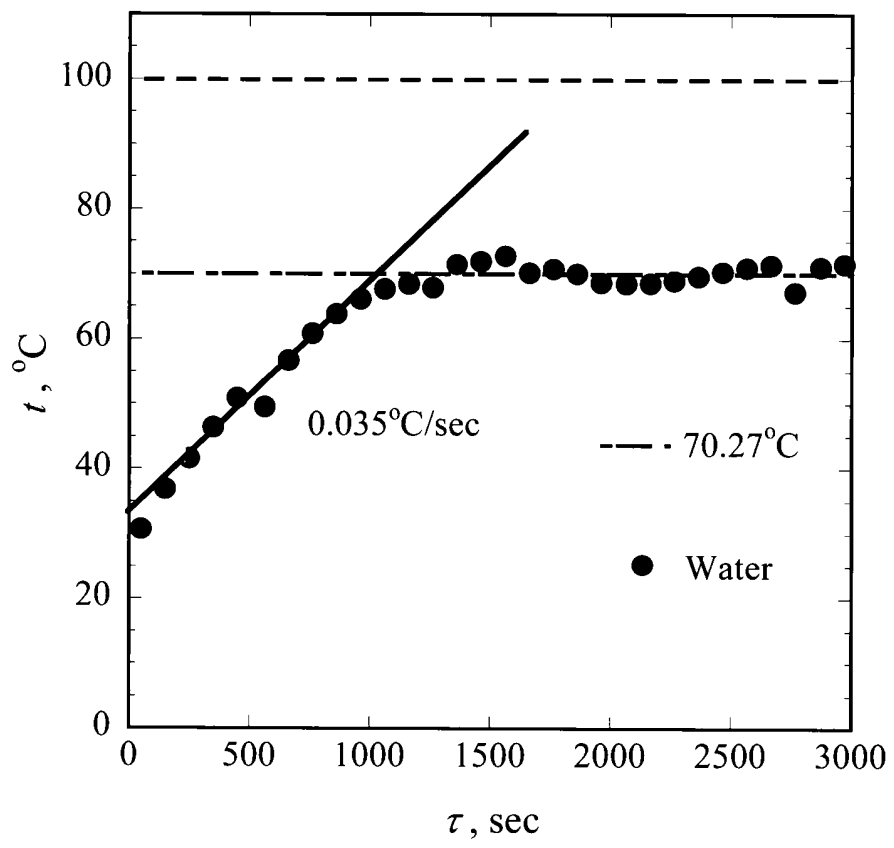

Fig.4 History of temperature within the stainless-steel container.

\section{Conclusions}

Here, the educational activities related to environmental topics and recycling carried out at engineering campus of Tamagawa University in the past 13 years from 1997 to 2010 are reported. For each theme, the set target was accomplished. Although, the achievements are important, the true accomplishment of the present curriculum is that students could engage in tackling social (or societal) problems, guided by their own thinking, to improve on their problem solving ability.

\section{References}

1)Yamamoto et al, Journal of JSEE 51-6 (2003), pp 90-95

2)Ohkubo et al, Experimental Education of Bicycle Recycling, Annual Meeting Society of Education for History of Technology, (2000), pp.12-14.

3)Suzuki et al, Japan Society of Mechanical Engineers Proceedings of Conference, (2005), pp.13-16.

4)Funaki,T.et al, Environmental and Recycling Education through a "Special Course for Active Students", Proceedings of the 5th International Conference on Business and Technology Transfer.

5)Ohkubo H, Japan Society of Mechanical Engineers 16th General Meeting of Kanto Branch Lecture, (2010), p.3.

6)Yoshida et al, Japan Society of Mechanical Engineers64th General Meeting of the Kyushu Branch of the lecture period, (2011), p.375. 